\title{
A regulação assistencial: uma revisão da literatura vs. uma hesitação da prática
}

\author{
Flávia Lopes Augusto SAMPAIO(1) \\ Samara Jamile MENDES ${ }^{(1)}$ \\ ${ }^{(1)}$ Faculdade de Saúde Pública, Universidade de São Paulo - USP, São Paulo, SP, Brasil.
}

Recebido: 28 jan 2019 Aceito: 10 fev 2019

Autor de correspondência: flavia.loas@gmail.com

Conflito de interesses: Os autores declaram não haver nenhum interesse profissional ou pessoal que possa gerar conflito de interesses em relação a este manuscrito.

\section{Resumo}

O Sistema Único de Saúde - SUS é um dos sistemas de saúde público mais complexos do mundo, pautado por três princípios: universalidade, integralidade e equidade, ele se desdobra em fundamentais diretrizes organizativas, que buscam garantir o seu funcionamento conforme prevê a Constituição Federal e a Lei 8.080/1990. Para uma prestação de serviço de qualidade à população e que atenda às necessidades, umas das diretrizes fundamentais do SUS é a descentralização de ações e serviços de saúde, a qual redistribui o poder e responsabilidade entre os três níveis de governo, ressaltando que os municípios devem ter condições gerenciais, técnicas, administrativas e financeiras para exercer esta função. $O$ processo de descentralização alcançou até a municipalização da gestão dos serviços, o que certamente representou a quebra de um paradigma. Assim, para cada esfera de poder regional (União, Estado e Município) haveria um responsável local, mas articulado com as outras esferas. Na gestão descentralizada do SUS, surge a necessidade de fortalecer o processo de regionalização, hierarquização e integração das ações e serviços de saúde, bem como a necessidade de fortalecimento dos instrumentos de gestão que garantem a organização das redes e fluxos assistenciais. Para isso instituiu a Política Nacional de Regulação em 2008 que se dividiu em três dimensões: a Regulação de Sistemas de Saúde, a Regulação da Atenção à Saúde e a Regulação do Acesso à Assistência, denominado também por alguns como Regulação de Acesso ou Regulação Assistencial. É essa temática especificamente no sistema referência e contrarreferência que surge a minha indagação e interesse sobre o assunto. O termo Regulação na área da saúde, tem vários desdobramentos, concepções e práticas. Trataremos nesse trabalho, a definição instituída pela Política Nacional de Regulação do Sistema Único de Saúde - SUS, focando na Regulação do Acesso à Assistência (regulação do acesso ou regulação assistencial), a qual possui como o objeto o acesso aos serviços de saúde e respectivos gestores. Afinal, para o Ministério da Saúde (2006), a regulação assistencial é o conjunto de relações, saberes, tecnologias e ações que intermedeiam a demanda das pessoas usuárias por serviços de saúde e o acesso a eles segundo diferentes perfis de demanda e de oferta, e a regulação do acesso 
é o estabelecimento de meios e ações, independente de pactuação prévia estabelecida na programação de ações e serviços de saúde e da disponibilidade de recursos financeiros. A regulação assistencial deve organizar a referência e contrarreferência entre os níveis de complexidade assistencial, orientando os processos de trabalho dos profissionais e seus gestores. Para isso, são necessárias sempre revisões e discussões da questão, de forma a permitir a sua utilização como instrumento aos profissionais da atenção básica, já que essa é a porta de entrada do SUS. Há necessidade de se instituir mecanismos mais eficazes da regulação assistencial e estabelecer uma operacionalidade melhor entre as instâncias, pois mesmo com portarias e decretos o acesso de serviços de saúde se mostra a cada dia mais difícil, mesmo considerando uma escassez nas ofertas, o que queremos tratar é a dificuldade do acesso visto que um dos papeis desse instrumento é ajudar no exercício da integralidade e não para cercear e dificultar a prática. Objetivo: fazer uma revisão da literatura sobre o tema da regulação assistencial e a integralidade Método: o trabalho em questão trata-se de uma revisão bibliográfica, embora o interesse pelo tema escolhido ter partido da prática profissional. É uma revisão narrativa, sistematizada que utilizou três descritores para sua busca na literatura. De acordo com o objeto de estudo escolhido, no caso a "Regulação Assistencial" foram encontrados cinco artigos governamentais extraídos do portal do Ministério da Saúde que nortearam e colaboraram para determinar as palavras chaves a serem pesquisadas nas bases dados da biblioteca virtual em saúde, isso porque no primeiro momento, a pesquisa pelo portal da Biblioteca Virtual em Saúde - BVS não trazia artigos que realmente tratassem o assunto desejado. Os descritores utilizados são: Gestão em Saúde, Regulação em Saúde e Acesso aos serviços de Saúde. No primeiro momento, foi realizado uma busca individual com cada descritor que trouxe o seguinte resultado: gestão em saúde (2880); regulação em saúde (42); e o acesso aos serviços de saúde (68448). Com as combinações dos descritores na BVS foi possível o seguinte retorno:" "Gestão em saúde" and "regulação em saúde" (8), "Gestão em saúde" and "Acesso aos serviços de saúde" (70) e "Regulação em saúde" and "Acesso aos serviços de saúde" (6). Resultados: para sistematizar e obter um resultado mais amplo, a sintaxe final do trabalho é: tw:(gestão em saúde)) $A N D$ (tw:(acesso aos serviços de saúde)) $A N D$ (tw:(regulação em saúde)) $A N D$ (instance:"regional"), a qual resultou em 153 artigos. Essa coleta de dados também não utilizou filtros e só após a busca selecionada que iniciou o processo de exclusão dos trabalhos que não estavam em acordo com o objetivo. Para excluir os trabalhos que não tratam a temática de estudo, foi feito a leitura de todos os títulos e resumos, após essa leitura foram excluídos os documentos que não abordavam sobre o sistema único de saúde brasileiro, a gestão da regulação de acesso aos serviços de saúde e os artigos duplicados. Esse processo de exclusão, resultou em 35 trabalhos, os quais foram submetidos ao registro na íntegra para um planilhamento e leitura completa posteriormente. Contudo, o assunto de interesse se mostrou um tema pouco discutido até o momento nas bases de dados e como já dito, por isso a necessidade de recorrer a uma 
pesquisa extra da plataforma BVS referenciando o assunto desejado, sendo incluindo cincos artigos governamentais extraídos do site do Ministério da Saúde, incluindo portarias e políticas.

Descritores: Gestão em Saúde; Regulação e Fiscalização em saúde; Acesso aos Serviços de Saúde. 